\title{
Transcription Initiation Factor IIA
}

National Cancer Institute

\section{Source}

National Cancer Institute. Transcription Initiation Factor IIA. NCI Thesaurus. Code C39781.

A protein complex that is required for RNA polymerase II-dependent transcription of

DNA. This complex is composed of transcription initiation factor IIA subunits 1 and 2 and is involved in the stabilization of the larger preinitiation complex. 